\title{
DENIS CALVAERT Y EL MONASTERIO BOLOÑÉS DE SAN MICHELE IN BOSCO: UNA PINTURA REDESCUBIERTA
}

Tenido por anónimo, el lienzo con Jesús curando a los enfermos se restituye aquí a Denis Calvaert, al tiempo que se asocia por primera vez a su dibujo preparatorio en el Louvre. La autora también identifica el cuadro con el perdido en el célebre monasterio boloñés de San Michele in Bosco, descrito a lo largo de la historia y tenido por una de las más bellas obras de su mano.

Palabras clave: Denis Calvaert; Dionisio fiammingo; Pintura Flamenca en Italia; San Michele in Bosco; Escuela boloñesa; Louvre; Dibujo preparatorio.

The previously anonymous Jesus healing the sick is here restored to Denis Calvaert, and linked for the first time to its preparatory drawing in the Louvre. The author likewise establishes that the painting, thought to have been lost, came from the Bolognese monastery of San Michele in Bosco, where it had been admired as one of his most beautiful works.

Key words: Denis Calvaert; Dionisio fiammingo; Flemish painting in Italy; San Michele in Bosco; Bolognese school; Louvre; Preparatory drawing.

Al margen de otras pinturas de notable interés (como un Cupido muy rubeniano que merece un estudio detenido), en la pasada subasta de Dorotheum retuvo nuestra atención un lienzo con Jesús curando a los enfermos de autor desconocido (fig. 1) ${ }^{1}$.

Pese al vacío en la autoría, y a lo particular de la representación (no muy del gusto del coleccionismo de nuestros días) su calidad no pasó inadvertida a la casa vienesa.

La composición está concebida en equilibrada geometría: cuatro diagonales articulan un rombo, con eje en la silueta de Jesús; y otras dos un aspa, con centro en la cabeza. Ésta es a su vez la cúspide de una pirámide, prolongada por la línea del brazo extendido hasta el enfermo en el primer plano a la izquierda y, al otro lado, por la cabeza de la mujer suplicante y la mano que sigue. Paralelo y en escorzo, un enfermo recostado en un lecho de paja dirige nuestra mirada en zig-zag hasta el fondo del escenario. Allí está el arco de una ciudad, con murallas afuera, junto a rocas y agua. De todos lados se encaminan los enfermos hacia Jesús: un tullido avanza con dificultad apoyado en su muleta, otro baja escaleras llevando un hombre a cuestas. El primer plano se inscribe en un círculo con movimiento helicoidal. Destacan los retorcidos cuerpos de los moribundos, con sus pétreas carnes mortecinas y sus jirones, así como las actitudes implorantes y estupefactas de los presentes. En contraste, la silueta del sanador reina estilizada y en elegante contraposto en el eje central, la mirada baja, el gesto humilde y compasivo, y un delicado nimbo sobre la cabeza.

${ }^{1}$ Lienzo, $146 \times 88 \mathrm{~cm}$, Old Master Paintings, Palais Dorotheum, 31.03.2009, n. ${ }^{\circ} 223$ (como Maestro flamenco hacia 1600). 
Todo está exquisitamente tratado, la técnica excelente, la obra en impecable estado de conservación.

No cabía duda de que se trataba de un buen pintor: con esto, pensamos que podía ser factible dar con su nombre. Se apuntaba en el catálogo como "Maestro Flamenco en torno a 1600". La atención prestada a los objetos y la calidad de las cosas, los modelos, el colorido y la técnica desvelaban un manierista nórdico de la segunda mitad del siglo XVI con maneras adquiridas en Italia bajo la influencia de Correggio: la pintura rondaría las últimas décadas del siglo.

Un desliz advertimos en la identificación del tema, que se tomó por La resurrección de Lázaro, lógica confusión que podría extenderse a otros de los numerosos milagros sanadores de Jesús que relatan los evangelios. Pero se trata aquí del episodio que tiene lugar en Galilea durante su predicación. La escena se identifica bien por la cantidad de seres desdichados. Es Jesús curando a los enfermos, acto milagroso que se lee así en Mateo [4, 23-24]: "Y rodeó Jesús toda Galilea, enseñando en las sinagogas de ellos, y predicando el evangelio del reino, y sanando toda enfermedad y toda dolencia en el pueblo. Y corría su fama por toda la Siria; y le trajeron todos los que tenían mal: los tomados de diversas enfermedades y tormentos, y los endemoniados, y lunáticos, y paralíticos, y los sanó". Esto responde a la pintura, pero hay discordancia en la introducción de cinco apóstoles, pues Mateo especifica que fueron cuatro los pescadores que en ese momento abandonaron sus redes para seguir a Jesús.

Falta también explicar la presencia, casi inadvertida, de un monje en posición orante en el ángulo izquierdo. Pensamos que debía tratarse de un retrato, y que el retratado debía ser el comanditario de la obra. Ningún atributo salvo su hábito, que lo asocia con la orden cisterciense. Podía tratarse de un monje blanco benedictino, o de un bernardino. Estas órdenes hicieron énfasis en las obras de misericordia. Nos pareció también posible que fuera alguno de sus santos más activos. A San Benito se le atribuyen varios milagros sanadores ${ }^{2}$, y San Bernardo de Claraval (aparte del conocido milagro en que recibe leche del seno de la Virgen) recibió también el don divino de la sanación, que le sirvió en numerosas curaciones de enfermos y moribundos (algunas de ellas conocidas en pintura). De hecho, la imagen de este monje no es ajena a la supuesta vera effigies de San Bernardo, ampliamente difundida. En cualquier caso, y sea quien fuere el monje de nuestro lienzo, se encuentra en contemplación mística de un asunto de la vida de Cristo para él muy ejemplar. Quizá el cuadro fuera encargo de algún miembro de la Iglesia con un sentimiento paralelo.

Establecidos estos puntos de orientación, y con el fin de averiguar el autor de la pintura, nos sometimos a una premeditada búsqueda con desenlace feliz. En el Museo del Louvre hallamos el dibujo preparatorio de la composición (fig. 2) ${ }^{3}$. Procede de la colección de Saint Morys, donde se tenía adscrito a Bartholomeus Spranger". Hoy figura, con dudas, como "atribuido" a Denis Calvaert (precisamente un flamenco que trabaja en Italia), y sin conocimiento del lienzo al que sirvió. La casi exacta correspondencia entre el dibujo y la pintura permitía afirmar la misma paternidad. Faltaba sólo corroborar que efectivamente era la del pintor propuesto. Cotejamos pues la pintura con otras seguras de su mano. Es idéntico el modelo del Cristo de la Flagelación de la Pinacoteca de Bolonia (fig. 3), una composición regida por las mismas directrices y con igual técnica. La comparación es extensible a los Desposorios místicos de Santa Catalina de los Museos Capitolinos, firmada y fechada en 1590, así como a otras obras de su mano.

\footnotetext{
2 Certain, E. De, Les miracles de Saint Benoît, Paris, 1868.

${ }^{3}$ Carbón, pluma, tinta ocre y aguada con realces de blanco, $319 \times 225 \mathrm{~mm}$. Procede de la colección Saint-Morys, anteriormente atribuido a B. Spranger. Paris, Département d'Arts Graphiques du Musée du Louvre [Inv. 20473, recto].

${ }^{4}$ Saint Morys, Inv. N. ${ }^{\circ}$ 20473/P625 [cf. LabBé, J. \& Bicart-SÉe, L. La collection Saint-Morys du Musée du Louvre (II). Repertoire des dessins, Paris, 1987, Cat. N. $\left.{ }^{\circ} 20473\right]$.
} 


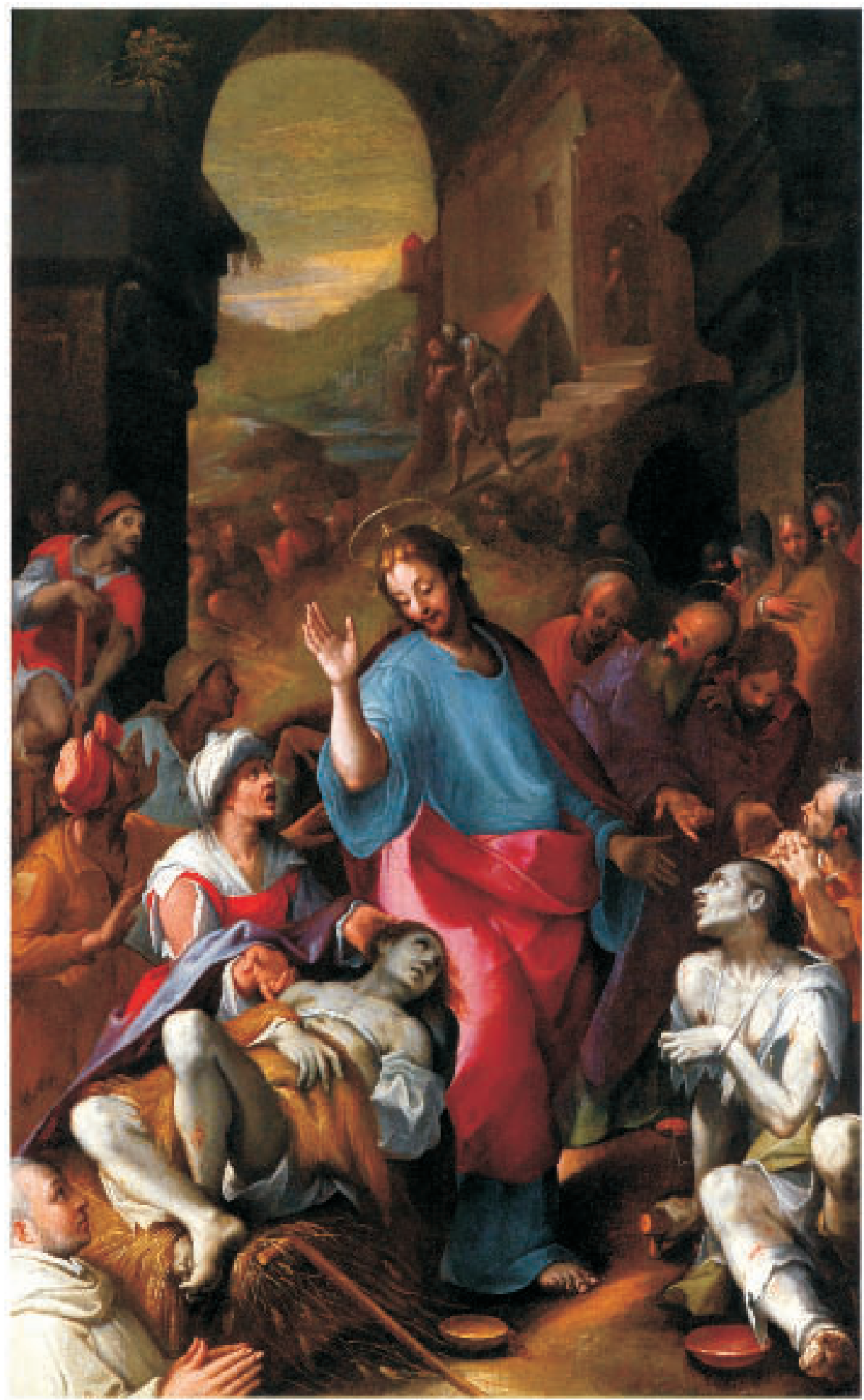

Fig. 1. Denis Calvaert. Jesús curando a los enfermos. Comercio de arte. 
Se trataba pues de Denis Calvaert (h. 1540-1619), del flamenco que fundó la escuela boloñesa, del maestro de Guido Reni, de Domenichino, de Francesco Albani y de tantos otros, del pintor que tanto influyó en los Carracci, en Italia conocido como "Dionisio Fiammingo".

Determinado su autor, fue infructuoso en un primer momento nuestro intento de localizar la obra en alguna antigua colección. La revisión de inventarios y demás documentación relativa al coleccionismo de la que disponíamos no dio resultados. A lo largo del siglo XVII, su nombre aparece repetidas veces en Italia, con obras en diversas colecciones de cardenales y nobles, y sólo una vez en su tierra natal: una pintura suya, hasta ahora inadvertida, quedó registrada entre las posesiones de Philip van Valckenisse, uno de los coleccionistas más notorios de Amberes, muerto en $1614^{5}$. No obstante, ninguna noticia localizamos de un milagro de Jesús.

Lo que sí hallamos fue una procedencia cercana, al ver la pintura citada en dos ventas durante los últimos años ${ }^{6}$. Cuál sería nuestra sorpresa cuando constatamos, no sin desconcierto, que en ambas ocasiones figuraba con su correcta atribución a Denis Calvaert. Ignoramos si Dorotheum no atendió a lo anterior, si lo rechazó o si lo desconocía, pero no deja de ser sorprendente para el investigador tal vuelta en bucle. En estos casos, es consuelo ver coincidir nuestras conclusiones con otras. No obstante, y al margen de estos devaneos, tras la asociación con el dibujo preparatorio y el análisis comparativo con su obra, no quedan motivos para dudar de la autoría de Denis Calvaert, tanto de la pintura en cuestión como del dibujo del Louvre.

El cotejo de ambos nos permite corroborar el proceso creativo observado líneas atrás: algunas de las líneas matrices que rigen la composición se distinguen en el dibujo. En este estadio quedan fijados casi todos los pormenores de la composición, con variaciones de escasa relevancia, en el cabello de Cristo, en la paja del suelo y en los personajes de la derecha. No obstante, en su paso al lienzo definitivo, modificó también la posición y escala del arco y la arquitectura, restando a la pintura algo del equilibrio y la coherencia compositiva con el resto de la escena que había logrado en el dibujo.

El influjo de Correggio es ostensible en la figura de Cristo: aunque invertido el ritmo de los brazos, recuerda al Noli me tangere del Museo del Prado (fig. 4). Sin duda Calvaert conocería esta pintura en Bolonia, mientras estuvo en casa de los condes de Ercolano ${ }^{7}$. De hecho, el préstamo es más literal en sus interpretaciones del mismo asunto ${ }^{8}$, reveladoras también de sus ejercicios con dibujos en sentido inverso9.

El rastro de Rafael persiste en el motivo del hombre llevando a otro sobre la espalda, recuerdo del fresco del Incendio del Borgo de las Estancias del Vaticano. Allí estuvo Calvaert en 1570, acompañando a su maestro Lorenzo Sabatini, para ocuparse de los frescos de la Sala Regia de Gregorio XIII, volviendo a Bolonia dos años después, para no moverse más. Cuentan que en Roma dibujó sin cesar a Rafael, y que sus dibujos provocaron un curioso encuentro con el papa. Malvasia habla largamente de él y abunda en anécdotas con sus maestros, alumnos y mecenas, y reproduce un grabado con su retrato (fig. 5) ${ }^{10}$.

5 "In de Salette oft Neercamer loor aen de Strate: Een schilderye Oprechtinge van 't Serpent in de woestyne gedaen by Denys Caluwaert" [DUverger, E., Antwerpse kunstinventarissen uit de zeventiende eeuw, Bruselas, 19842002, vol. I, p. 306].

${ }^{6}$ Londres, Sotheby's Old Master Paintings Day, 7/12/2006, n. ${ }^{\circ} 192$ (como Cristo en el Purgatorio); Stuttgart, Nagel Gemälde Alter Meister Skulpturen / Plastiken, 19/09/2007, n. ${ }^{\circ} 595$ (con correcta identificación)

${ }^{7} \mathrm{Al}$ menos desde 1560 [cf. LAMO, P., Graticola di Bologna: ossia descrizione delle pitture, sculture e architetture della città: fatta l'anno 1560, Bolonia, 1844, p. 13; cit. EksERdJIAn, D., Correggio, New Haven, 1997, pp. 156-159].

${ }^{8}$ Conocido por dos dibujos y dos lienzos: Lienzo, 152 x $144 \mathrm{~cm}$. Bolonia, Pinacoteca Nazionale [Inv. 494]. Una réplica se encuentra en el Museo de Varsovia [Inv. 129451].

9 Véase W. KLoeK, Th., "Calvaerts oefeningen met spiegelbeeldigheid", Oud Holland, n. ${ }^{\circ}$ 107, 1993, pp. 69-70.

${ }^{10}$ Malvasia, C., Felsina Pittrice. Vite de pittori Bolognesi..., vol. I, Bolonia, 1678, pp. 248-263. Noticias que transmite también Fetis, E., Les artistes belges à l'étranger, études biographiques et critiques, II, Bulletins de l'Académie Royale des Sciences et Belles-Lettres de Bruxelles, Bruselas, 1859, pp. 155-180. 


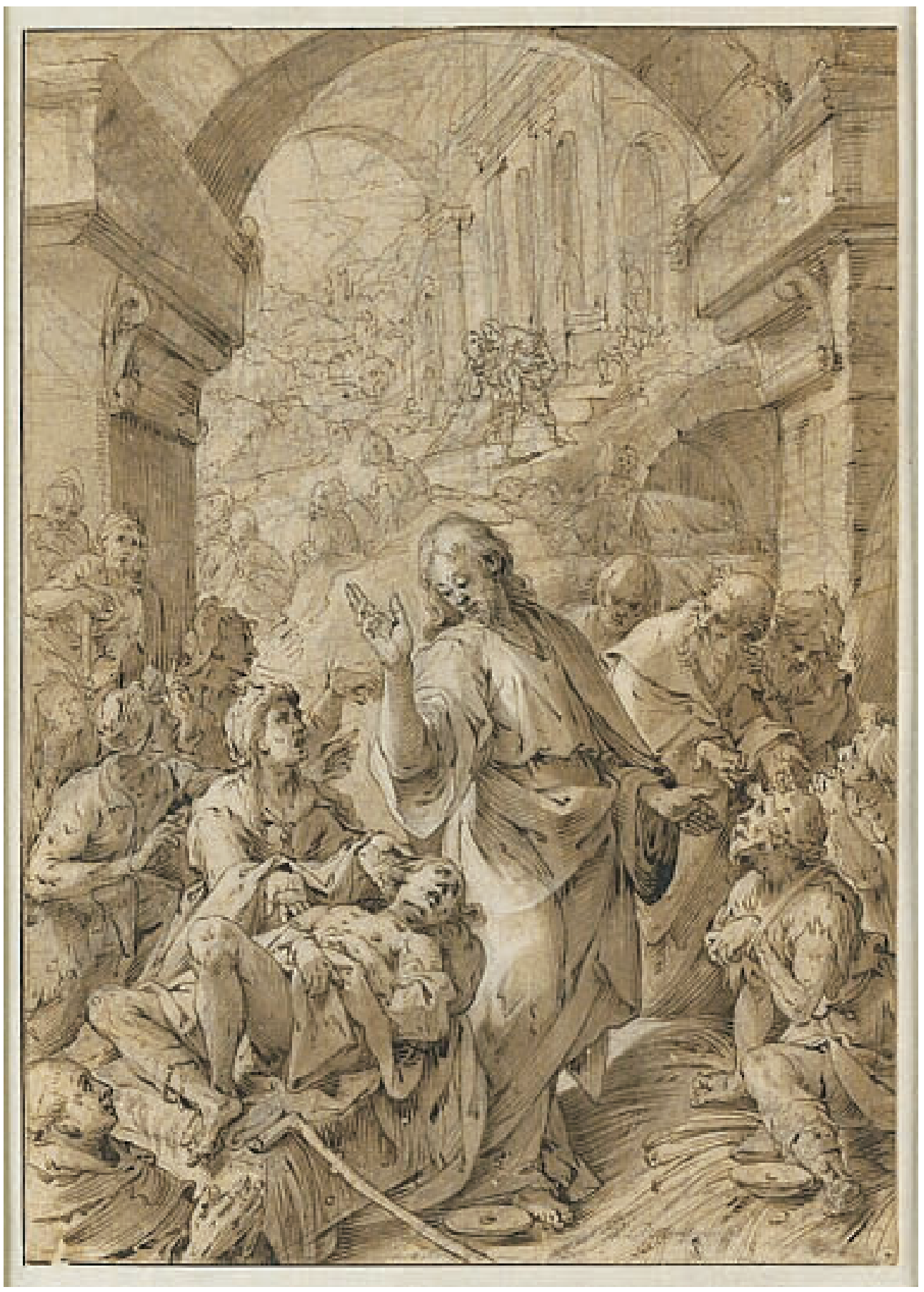

Fig. 2. Denis Calvaert. Jesús curando a los enfermos. Dibujo sobre papel. París, Musée du Louvre, Département d'Arts Graphiques [inv. 20473]. 


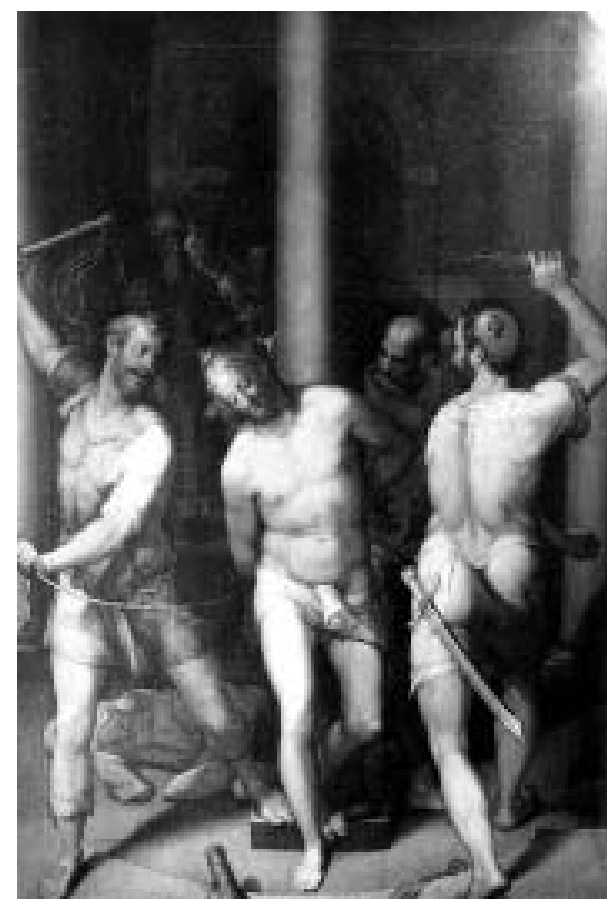

Fig. 3. Denis Calvaert. Flagelación de Cristo. Bolonia, Pinacoteca Nazionale [Inv. N. ${ }^{\circ} 488$ ].

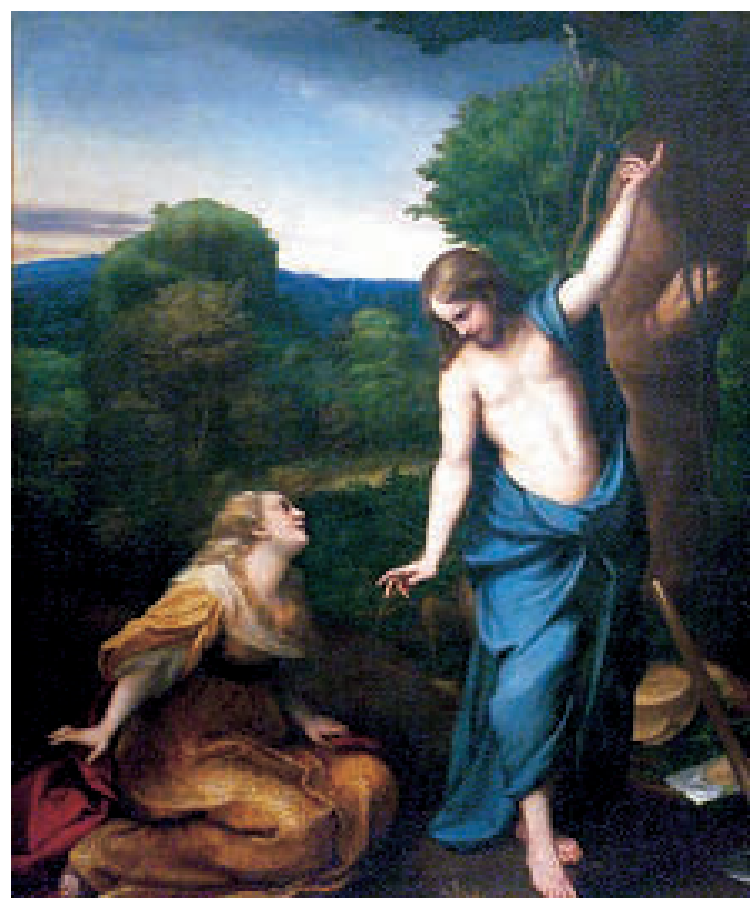

Fig. 4. Correggio. Noli me Tangere. Tabla pasada a lienzo. Madrid, Museo Nacional del Prado [Inv. N. ${ }^{\circ}$ P111].

Jesús curando a los enfermos confirma con evidencia el interés del pintor por la arquitectura, la perspectiva la geometría y la anatomía, principios que trasmitió con insistencia a sus discípulos. Su comentada firmeza en la práctica del dibujo se materializa en el estructurado trabajo preparatorio de esta composición madurada.

Pese a su adopción transalpina, no olvidó Calvaert su formación. Había sido aprendiz en Amberes junto al desconocido paisajista Kerstian van Queckborne. Así lo atestan los registros de la guilda de pintores de la ciudad del año 1556, en que Calvaert figura como su alumno ${ }^{11}$. La habilidad de Calvaert para el paisaje se evidencia en el fondo de la composición, pero el pintor modera aquí la manera lamida típicamente flamenca que fue el reproche de su primer maestro en Italia, Prospero Fontana ${ }^{12}$. No obstante, se impone el sentimiento nórdico realista y el sentido del color, y la adopción atemperada del manierismo italiano que le caracteriza. Calvaert combinó con éxito ambas tendencias: al realismo unió el rigor del dibujo y el del color, creando el estilo híbrido que percibimos.

Aunque olvidado hoy, Denis Calvaert se recuerda en las páginas de la historia como el fundador de la escuela boloñesa, fama que persistía aún con fuerza en la Italia del siglo XIX, cuando

\footnotetext{
11 “1556, Denys Caluwaert by Meester Cerstian Queckborne Schilder” [cf. Rombouts, Ph. \& Van Lerius, Th., De Liggeren en andere historische archieven der Antwerpsche Sint Lucasgilde, Amberes, 1864-1876, Amberes, 1961, vol. I, p. 199].

12 Malvasia, op. cit., 1678, p. 251.
} 


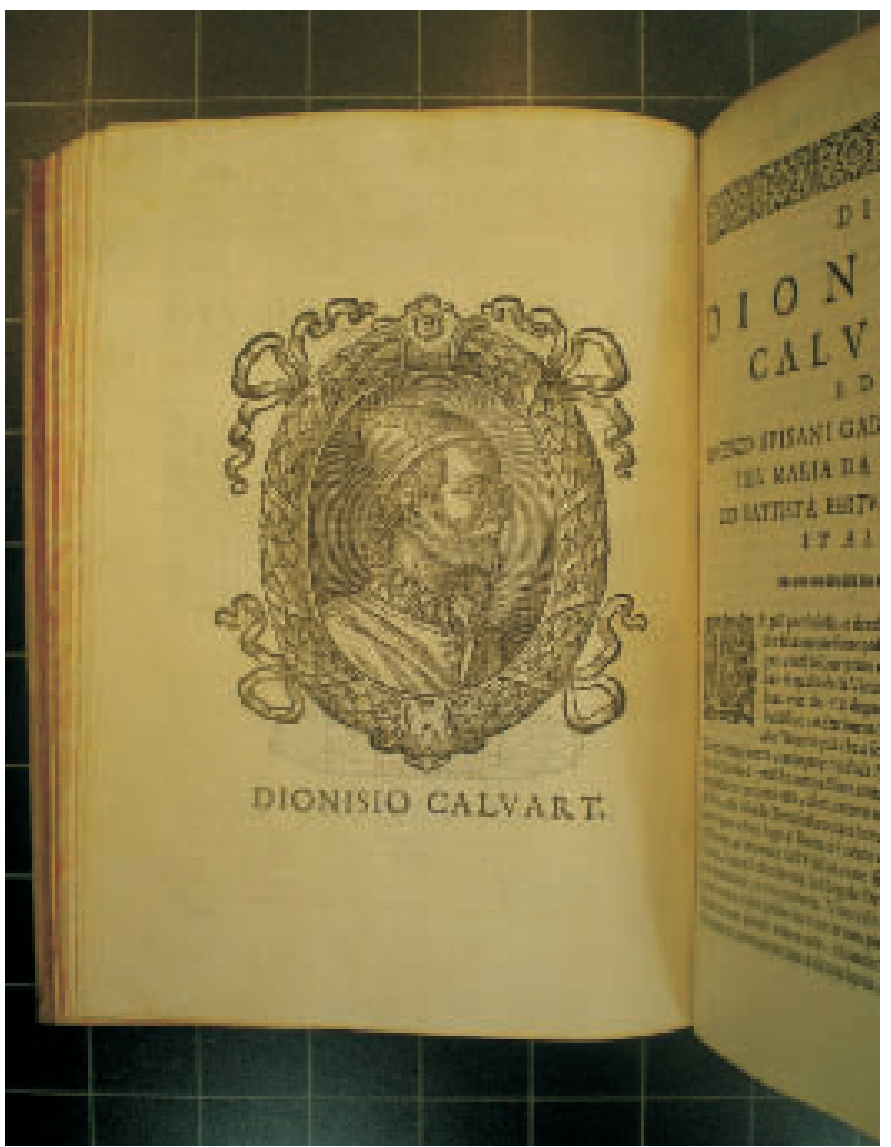

Fig. 5.

Antonio Bolognini Amorini escribió las Memorie delia vita del pittore Dionisio Calvart (1832), al tiempo que hacía restaurar la inscripción de su tumba (en la iglesia boloñesa Dei Serviti, 1619), ornándola de un retrato del pintor flamenco.

Con estas líneas concluíamos cuando cayó en nuestras manos el último trabajo monográfico sobre el pintor, publicado por S. Twiehaus en $2002^{13}$. Allí estaba la clave de la procedencia e intencionalidad de la pintura, pues referenciaba, entre las obras perdidas, un "Cristo curando a los enfermos" de la Capilla de la Enfermería del Monasterio de San Michele in Bosco, en Bolonia. Así la registra Antonio Masini en su Bologna Perlustrata de 1666: “(...) de mano de Dionisio Calvart, que tan bien pintó en la capilla de la enfermería un cuadro, donde Cristo sana a muchos de diversas enfermedades" 14 . También Malvasia (1678) dejó constancia de la obra en el

13 Twienaus, S., Dionisio Calvaert (um 1540-1619). Die Altarwerke, Berlín, 2002. Véanse también los trabajos pioneros de Bergmans, S. [Catalogue critique des Oeuvres du peintre Denis Calvart, Académie Royale de Belgique, Mémoires 3, Bruselas, 1931; "Denis Calvart, Antwerpsche Schilder, stichter der Bologneesche school der XVIe eeuw", Onze Kunst, XLV, 1928, pp. 202ss; "Denis Calvart", La Revue de l'Art, 45, 1928, pp. 164-179; Denis Calvart, Peintre anversois, Fondateur de l'école bolonaise, Académie Royale de Belgique, Mémoire 4, Bruselas, 1934].

14 “(....) di mano di Dionigio Caluart, che molto ben dipinse nella Capaletta dell'Infermaria una tavola, dov'è Christo, che molti da varie infermità risana" [MAsinI, A., Bologna perlustrata. Terza impressione notabilmente accrescivta, Bolonia, 1666, pp. 127-128]. 
monasterio olivetano, informando de que era la escena central de un tríptico: "Cristo sanando todo tipo de enfermos, en la tan bien ornada capilla de la enfermería, con santos laterales de un alumno suyo, retocados por él"15.

En el siglo XVIII, Oretti la registra en el Hospital, señalando una inscripción: "1595. Apprile"16, de cuya existencia no tenemos constancia. Quizá estuviera en alguno de los santos laterales. En cualquier caso, tal fecha situaría a Cristo curando a los enfermos poco antes de la Resurrección de Lázaro del Claustro de las Benedictinas de Seedorf, Suiza $(1598)^{17}$, cronología difícil de aceptar si comparamos los desnudos de ambas pinturas: la anatomía de Lázaro en aquella obra dista mucho del realismo y proporción de los dos enfermos aquí, en perfecto contrahecho y dispuestos en logrado escorzo. Las analogías son mayores con la Virgen con Niño y Santos de $1606^{18}$.

De 1599 se conoce un pago de 300 liras al pintor por otro "retablo de altar" para los monjes del monasterio de San Michele ${ }^{19}$, un San Pedro entregando las llaves a San Clemente, hoy en la Pinacoteca di Brera de Milán ${ }^{20}$. Parece posible que ambos encargos estuvieran próximos en el tiempo.

En cualquier caso, para Dézalier d'Argenville (1752), fueron estas dos pinturas los "dos cuadros más bellos de Denis Calvaert" "21, noticia hasta ahora inadvertida y no falta de significación. Es lógico que el pintor se haya esmerado en extremo, tenida cuenta de la importancia artística y política del conjunto monástico para el que se destinaba la obra. En lo alto de una colina al sur de Bolonia se alzaba como una fortaleza el conjunto. Sus orígenes están en el siglo IV, pero fue en 1364 cuando los olivetanos emprendieron la reconstrucción, y desde que Eugenio IV pusiera la primera piedra, el conjunto ha vivido a lo largo de su historia diversas reestructuraciones. No podemos dejar de señalar su iglesia renacentista, su famoso claustro octogonal diseñado por Pietro Fiorini, el Refectorio o Sala Vasari, la Foresteria con los frescos de Carracci, y la espléndida biblioteca diseñada por Canuti ${ }^{22}$.

15 "Christo ché risana ogni sorti d'infermi, entro la Capella si ben ornata dellinfermeria, co' Santi Laterali d'un suo allievo, da lui ritocchi” [Malvasia, C., Felsina Pittrice. Vite de pittori Bolognesi..., vol. I, Bolonia, 1678, p. 254].

${ }^{16}$ Oretti, M., Le Pitture nelli Palazzi, e Case di Villa nell Territorio Bolognese (A), Pitture nelle Chiese fuori della Città di Bologna ne Suburbij e nelli Castelli, ed altre Chiese del Territorio Bolognese (B), BCM, Ms. Leg. 110, ff. 28, 125; Idem, Notizie de' prpfessori del disegno cioè pittori, scultori ed architetti bolognesi e de' forestieri di sua scuola raccolte ed in più tomi divise da Marcello Oretti bolognese académico dell'istituto delle scienze di Bologna, BCB, Ms. Leg. 124, II, ff. 102; [Cit. TwieHAus, op. cit. 2002, p. 238].

17 Vid. Twiehaus, op. cit. 2002, p. 232, n. ${ }^{\circ}$ A34.

18 Lienzo, 266 x 172 cm. Fechado en 1606. Bolonia, Convento de San Luca [Twiehaus, op. cit. 2002, p. 199, n. ${ }^{\circ}$ A9]

19 “1599. Si fabbrica una sepultura per i monaci: Dioigi Calvart fa l'ancona dell'altare per lire 300 L” [Archivo, San Michele in Bosco, Bolonia, Cit. ZucchinI, G., "S. Michele in Bosco di Bologna", L'Archiginnasio, 38, 1943, p. 31; TwiEhaus, op. cit. 2002, p. 175, doc. 26].

${ }^{20}$ En depósito en la Iglesia de San Alessandro en Copreno, Milán [TwieHaus, op. cit. 2002, p. 218, n. ${ }^{\circ}$ A24].

21 "Ses deux plus beaux tableaux sont dans le Cloître de Saint Michel in Bosco, c'est Saint Pierre qui donne les clefs au Pape Clément, \& un Christ qui guérit les malades de la Chapelle de l'infirmerie de ce Couvent" [DEzallier D’Argenville, A. J., Supplément à l'Abrégé de la Vie des plus fameux Peintres, 3ème partie, 1752, p. 174].

22 Malaguzzi Valeri, F., La chiesa e il convento di S. Michele in Bosco, Bolonia, 1895; Zucchini, G., "San Michele in Bosco di Bologna", L'Archiginnasio. Bullettino della biblioteca comunale di Bologna, 38, 1943, pp. 1870; Malvasia, G. C., Giovannini, G. M., Roversi, G., Campanini, M. S., Il Claustro di San Michele in Bosco, Bolonia, 1988; Bertoli Barsotti, A. M. \& Cioni, A., L'Istituto Rizzoli in San Michele in Bosco (1896-1996). Il patrimonio artistico dell'Abbazia Olivetana e vicende storiche di cento anni di chirurgia ortopedica, Milán, 1996. 
De interés son sus ligazones con España. Carlos V se detuvo allí durante su doble coronación en 1530 , y admiró sus notables pinturas ${ }^{23}$. El hospital alojó también a Carlos III siendo príncipe ${ }^{24}$, y fueron estrechas las relaciones del Colegio de España con el conjunto monástico y sus abades ${ }^{25}$. Tuvo un papel determinante en las artes, albergando frescos e importantes pinturas ${ }^{26}$, además de relevantes personalidades y coleccionistas del momento ${ }^{27}$. Quizá alguno se detuviera a rezar, en el altar de la Capilla de la Enfermería, ante este lienzo de Denis Calvaert.

El destino de la obra condicionó pues la naturaleza del asunto. Se trataba de mostrar una imagen ejemplar, al tiempo que invitar a meditar sobre este milagro de Jesús, y trasmitir principios de misericordia y caridad. Es la idea que debió animar al comanditario de la pintura, probablemente el abad, que se hizo representar en el margen inferior y cuyo nombre desconocemos. Calvaert previó su retrato en el dibujo preparatorio, igual que en otras obras de su mano con presencia de donantes ${ }^{28}$, lo que no deja de ser revelador de una tendencia recurrente y posiblemente arrastrada de su formación, pues este recurso realista es más común en sus precursores flamencos que en los italianos que le inspiran.

La pintura permaneció en el monasterio hasta la llegada de las tropas napoleónicas. Tras la toma de Bolonia en 1796, Napoleón firmaba un armisticio que comprometió numerosas obras de arte. El Monasterio de San Michele in Bosco fue suprimido en 1797 y, dada su posición estratégica, se convirtió en cuartel de la soldadesca; posteriormente fue penal (1804), villa del cardenal Spinola (1843) y Villa Real (1860). Desde 1896, y por voluntad del cirujano Francesco Rizzoli, es sede de un instituto médico.

En tiempos napoleónicos, vivía en la colina de enfrente el ministro Aldini, en una villa antigua que aún lleva su nombre, después ocupada por el ejército austriaco ${ }^{29}$. Vivant Denon recorre los monasterios suprimidos por toda Italia, seleccionando obras para completar la colección imperial. "De más de 6.000 cuadros - dice en carta del 9 de marzo de 1812-, sólo he designado unos 72 de maestros totalmente desconocidos en Francia; no he marcado una sola obra de cuyo pintor posea ya el museo alguna producción, buscando siempre conciliar los intereses locales con los de Su majestad"30. Con la supresión de los monasterios, muchas obras se llevaron al museo

23 'L'imperatore Carlo venne al sontuoso Monastero di san Michele in Bosco, siccome uno di que' luoghi che teneansi in maggiore rinomanza tra i più celebri d'Italia" [cit. GIORDANI, G., Della venuta e dimora in Bologna del sommo Pontifice Clemente VII. per la coronazione di Carlo V. Imperatore: celebrata l'anno MDXXX. Cronaca con note documenti ed incisión, Alla volpe, 1842, p. 49, continúa con las pinturas que allí admiró].

24 “Dell'Anno de 1732 li 7 Ottobre, Il principe Reale D. Carlo di Borbon, Infante di Spagna, nel suo passagio per Parma, e Piacenza, aloggiò nel sudetto Monastero di S. Michele, ed amise al bacio delle mani gli P.P. Abbati" [cit. García Cueto, D., Seicento boloñés y siglo de oro español: el arte, la época, los protagonistas, Madrid, 2006, p. 47].

25 "El colegio de España y su proyección en Bolonia", en GARCía PrIETo, op. cit. 2006, p. 47; GARCía VALDECASAS, J. G., Las Artes de la Paz. Ensayos: Homenaje de Ceeh a treinta años de rectorado en el Real Colegio de España en Bolonia, 2007, p. 342.

${ }^{26}$ Campanini, M. S., Terra, R., Santucci, A., Il Chiostro dei Carracci a San Michele in Bosco, Bolonia, 1994.

27 Por estas fechas está en el monasterio el músico Adriano Banchieri, que sería abad años más tarde, en 1620 [Bartholomew, L., Adriano Banchieri: Canzoni Alla Francese of 1596, A-R Editions, 1975, p. 7]. En 1598 lo visita el Papa Clemente VIII, en 1624 la Duquesa de Mantua, en 1626 el Archiduque Leopoldo, en 1628 el Gran Duque de Toscana, y Cristina de Suecia en 1655 [cit. Paltrineri, A. (ed.), Il Monastero di San Michel in Bosco e L'Istituto ortopédico Rizzoli, Bolonia, 2006, p. 14].

28 Véanse la Virgen del rosario en gloria rodeada de santos de 1612 y la Crucifixión con San Jerónimo con donantes de la Pinacoteca de Bolonia (Inv. 7073) [Twiehaus, op. cit. 2002, Cat. A29 y A18].

29 Murray, J., A Handbook for Travellers in Central Italy, Londres, 1857, p. 63.

${ }^{30}$ Carta de Denon al Intendente General de la Corona, del 9 de marzo de 1812 [Paris, Archives des Musées Nationaux [Reg. AA8 p. 186 Denon]. Vid. Dupuy, M. A., Masne de Chermont, I. le, Williamson, E., Vivant Denon: Directeur des musées sous le Consulat et L'Empire. Correspondance (1802-1815), París, Editions des Musées Nationaux. 
de Brera ${ }^{31}$. De hecho, fue lo que sucedió con el otro cuadro de Calvaert que se encontraba en el Monasterio boloñés. Éste quedó allí, pero el de Jesús curando a los enfermos debió salir y perderse en el trasiego de obras de arte y el traslado de muchas para el museo de Roma y la decoración de los palacios imperiales ${ }^{32}$.

En cualquier caso, a mediados del siglo XIX, viajeros ingleses de visita al monasterio comentan el saqueo francés, lamentándose del deterioro de los frescos y de la desaparición de las pinturas ${ }^{33}$.

Ignoramos el paradero de Jesús curando a los enfermos hasta su reciente aparición en subasta de 2006, en cuyo catálogo se señala como procedente de la colección de Mr. Steinort de Londres, según etiqueta al dorso, que informa también de su exposición en Karlsruhe en fecha indeterminada.

Son pocas las pinturas de Denis Calvaert de las que se puede seguir el rastro en España: su nombre parece haberse diluido en la historia del coleccionismo de nuestro país. Sabemos sólo de una pintura suya (hoy sin localizar e inadvertida en la monografía del pintor) que tuvo un español en su colección, el Marqués de las Marismas, Alejandro Aguado y Ramírez, exilado en París desde 1815. Representaba un tema no muy lejano del que nos ha ocupado hoy: la Resurrección de la hija de Jairo, cuadro imponente en tamaño y número de figuras, referido en el catálogo de su colección (1841) $)^{34}$ y comprado en subasta tras su muerte por Baudicour ${ }^{35}$.

"El primer maestro de la escuela boloñesa -se apunta en la introducción de aquel catálogo de 1841- sólo es conocido hoy por la deserción de sus alumnos, que lo abandonaron atraídos por los Carracci y lo novedoso. Es un curioso ejemplo de lo azaroso y fugitivo de la fama" 36 .

Para contrarrestar el olvido están afortunadamente las obras, y el trabajo de los investigadores: así, las dos pinturas del Museo del Prado recuperadas por Ana Diéguez del anonimato (y estudiadas en las páginas precedentes), dan prueba de que el silencio documental respecto al pintor en España no responde a una realidad.

JAHEL SANZSALAZAR Instituto Moll

\footnotetext{
31 Así se entiende por carta de Denon al Ministro del Interior, con fecha de 16 de enero de 1812: “J'ai visité (...) le musée de Brera, déjà magnifique par la réunion que le prince y a faite de la belle collection Zamperi, et des tableaux provenant des monastères supprimés" [cf. Paris, Archives des Musées Nationaux, [Reg. AA8 p. 76]. Vid. Op. cit. supra].

32 Véase la carta de Denon al Intendente General de la Corona, del 21 de diciembre de 1811 [AMN, Reg. AA12, correspondance supplémentaire, p. 182].

33 "Many of the paintings have entirely disappeared, and of those which remain the subjects are hardly to be distinguished" [MurraY, ibidem, p. 62]. "It was the French invasion that desecrated this beautiful spot consecrated to religion. Its cloisters and halls were occupied as barracks and hospitals and prisons its halls were stripped of their paintings which were carried to Paris and the numerous and beautiful frescoes of the Carracci and Guido and their schools are water soaked and cracked and streaked and gone to cureless ruin" [BENEDICT, E. C., A Run Through Europe, Londres, 1860, p. 270].

34 "Calvaert ou Calvaert (Denis): Jésus chez la femme malade. Haut $2 \mathrm{~m} 80$ c.; larg. $1 \mathrm{~m} 78$ cm" [Catalogue des tableaux des écoles espagnoles, italiennes, flamande, hollandaise, allemande exposés dans la galerie du Marquis de las Marismas, Paris, 1841, p. 85, n. $\left.{ }^{\circ} 258\right]$.

35 “Jésus ressuscitant la Fille de Zaïre. Sept figures. 280-178, vente Aguado, 330 Fr, à M. de Baudicour” [cit. Defer, P., Catalogue général des ventes publiques de tableaux et estampes depuis 1737 jusqu'à nos jours: contenant, 1, les prix des plus beaux tableaux, dessins, miniatures, estampes,...2, des notes biographiques formant un dictionnaire des peintres et des graveurs les plus célèbres de toutes les écoles, Paris, 1868, p. 234, n. $\left.{ }^{\circ} 2\right]$.

${ }^{36}$ Catálogo Aguado, op. cit. supra 1841, p. XV.
} 